\title{
DERECHO URBANÍSTICO, PLANIFICACIÓN TERRITORIAL Y OTROS RETOS TRAZADOS POR LA PANDEMIA DEL COVID-19
}

\author{
Iván Ortiz Sánchez \\ Pontificia Universidad Católica del Perú \\ Carlos Ignacio Valencia Mesías \\ Autoridad de Transporte Urbano para Lima y Callao (ATU) \\ Ximena Alejandra Vílchez Vargas \\ Pontificia Universidad Católica del Perú
}

\begin{abstract}
Resumen: ¿Cómo afecta la pandemia del COVID-19 a las ciudades? ¿Cuál es el impacto de las medidas adoptadas para combatir dicha enfermedad respecto del derecho urbanístico? ¿Cuáles son los principales retos impuestos por dicha enfermedad a esta rama del derecho administrativo? El presente artículo busca dar respuesta a estas interrogantes a partir de la definición de derecho urbanístico y los principales ejes que conforman su contenido. Asimismo, se analiza el impacto de las nuevas políticas de distanciamiento social dentro de los espacios públicos, así como en el servicio de transporte. Por último, se esbozan unas breves reflexiones sobre la importancia de la vivienda como espacio para la convivencia y continuidad de actividades de los ciudadanos en este contexto actual.
\end{abstract}

Palabras Clave: pandemia COVID-19, derecho urbanístico, ordenamiento territorial, transporte público, espacios públicos, vivienda. 


\title{
Urban law, territorial planning and challenges imposed by COVID-19 pandemic
}

\begin{abstract}
COVID-19 Pandemic has created different challenges for Peruvian cities. How Urban Law and urban regulation should respond to those challenges? The article tries to respond to this question by revisiting the concept of Urban Law and the principles that are behind it. Moreover, the article will explore the impacts that the social distancing policies have had in territorial planning, public transport and public spaces and how this new context requires a reframe in the policies that regulate those sectors. The final section is dedicated to highlighting the importance of housing in the social distancing context and how the housing regulation should evolve to create a real safe-place from the risks imposed by the COVID-19 that allows the continuity of life in this new reality.
\end{abstract}

Keywords: COVID-19 Pandemic; Urban Law; Territorial Planning, Public Transport, Public Spaces, Housing.

Agradecemos a Erick Lau Gastelo, miembro e investigador del Grupo de Investigación, Urbanismo, Gobernanza y Vivienda Social (CONURB) de la Pontificia Universidad Católica del Perú, por la revisión y comentarios de la última versión de este documento.

\section{Iván Ortiz Sánchez}

Profesor Asociado de la Pontificia Universidad Católica del Perú y de la Academia de la Magistratura. Abogado y Magíster en Derecho Constitucional. Es Miembro del Consejo Directivo del Organismo de Evaluación y Fiscalización Ambiental. Ha sido Vocal del Tribunal Nacional de Resolución de Controversias Hídricas de la ANA (20142017). Es miembro del Grupo de Investigación de Derecho Ambiental y del Grupo de Investigación CONURB PUCP.

Correo: iortiz@pucp.edu.pe 


\section{Carlos Ignacio Valencia Mesías}

Abogado por la Pontificia Universidad Católica del Perú, con Especialidad en Derecho Administrativo. Maestrista con mención en Derecho Constitucional y Derechos Humanos por la Universidad Nacional Mayor de San Marcos. Es abogado en la Autoridad de Transporte Urbano para Lima y Callao (ATU). Adjunto de Docencia en el curso «Derecho Urbanístico» de la Facultad de Derecho de la PUCP. Miembro asociado del grupo CONURB de la PUCP. Ex miembro y director de la Comisión de Publicaciones de la Asociación Civil Foro Académico de la PUCP (20142020).

Correo: carlos.valenciam@pucp.pe

\section{Ximena Alejandra Vílchez Vargas}

Bachillera en Derecho por la Pontificia Universidad Católica del Perú. Adjunta de Docencia en el curso «Derecho Urbanístico» de la Facultad de Derecho de la PUCP. Miembro asociado del grupo CONURB de la PUCP. Ex miembro de la Comisión de Actualidad Jurídica de la Asociación Civil Foro Académico de la PUCP (2017-2019) y ex integrante del Grupo de Estudio en Derecho Inmobiliario (GEDI) de la UNMSM.

Correo: xvilchez@pucp.pe 


\section{Introducción}

Las pandemias a lo largo de la historia han impactado en las sociedades, en la formación o transformación de las ciudades y en el derecho. Al respecto, García Novo (2020) indica: «(...) ya la peste negra del siglo XIV alteró su fisionomía [de los espacios urbanos] por el éxodo rural masivo. El cólera transformó las urbes en el siglo XIX para proteger a sus ciudadanos». Ahora, el COVID-19 (2019), cuyo impacto mundial se dio apenas en meses, también modificará los espacios urbanos. En el Perú, el primer caso detectado del virus se dio el 6 de marzo de 2020, apenas cuatro meses después de que fuera detectada en Wuhan (China), una ciudad (metrópoli) de 11 millones de habitantes que la OMS (2020) indica como el epicentro del origen del virus.

Tomando en cuenta el impacto que ha tenido la pandemia en las urbes del mundo, en este artículo nos preguntamos por los impactos y los retos de la pandemia generada por el COVID-19 en el derecho urbanístico, específicamente en el ordenamiento territorial, el urbanismo y la vivienda.

Para ello, inicialmente plantearemos una definición del derecho urbanístico y los ejes principales de su contenido. En segundo lugar, desarrollaremos los retos trazados por el COVID-19 en el ordenamiento territorial (destacando el impacto de la pandemia en el transporte público), en el urbanismo (haciendo énfasis en los espacios públicos) y la vivienda. Finalmente, esbozaremos unas breves reflexiones que sinteticen lo abordado en los apartados anteriores, destacando el importante rol que debe cumplir el derecho urbanístico en este nuevo contexto social. 


\section{Aproximación al Derecho Urbanístico}

Como punto de partida, nos valemos de la definición brindada por Ortiz sobre el derecho urbanístico:

[El derecho urbanístico constituye] El conjunto de normas y principios que regulan
la función pública del urbanismo sobre las ciudades y las áreas metropolitanas. Por
lo tanto, se trata de normas y principios que regulan la planificación urbana, el uso
y control del suelo, el contenido de la propiedad predial urbana y la ordenación
del territorio, su ejecución y la regulación de la edificación. Todo ello con el fin de
racionalizar la acción pública y privada sobre el territorio, proyectando un desarrollo
urbano sostenible sobre los espacios urbanos formales, incorporando a los espacios
informales y generando alternativas para promover su progresiva desaparición como
medio para el crecimiento urbano y el acceso a la vivienda (Ortiz 2017: 31-32).

Como puede apreciarse, esta definición plantea un contenido integrador, partiendo de la planificación y el desarrollo urbano sostenible, sin dejar de lado la finalidad que cumple esta rama del derecho. En ese sentido, los principales ejes y contenidos que esta rama regula son los siguientes: la planificación urbana (ordenamiento territorial), la zonificación, los espacios públicos, la vivienda, habilitaciones urbanas, renovación urbana, edificación y control urbanístico (desarrollando su estrecha relación con el régimen del suelo, los derechos de propiedad y el interés general).

De estos ejes o contenidos del derecho urbanístico, revisaremos, a efectos del presente artículo, los retos de la pandemia generada por el COVID-19 sobre el ordenamiento territorial, el transporte público, los espacios públicos y la vivienda.

\section{Retos Planteados para el Ordenamiento Territorial: Una Nueva Visión Integral}

Uno de los impactos más notorios que el contexto de pandemia por el COVID-19 ha dejado en relación con el derecho urbanístico es, sin duda alguna, el concepto y aplicación del ordenamiento territorial. Asimismo, y de modo particular, la adopción de mecanismos empleados para prevenir y combatir contra dicha enfermedad (tales como el aislamiento o el distanciamiento social) han influenciado significativamente en las diversas actividades económicas realizadas por la población - ya sea de forma negativa o positiva-, como es el caso del servicio de transporte público y el uso de mecanismos alternativos de movilidad (por ejemplo, las ciclovías).

En tal sentido, en el presente apartado abordaremos brevemente cada uno de estos aspectos, resaltando sus particularidades, así como armonizando sus consecuencias a efectos de poder resaltar — como respuesta a los mismos- la necesidad de repensar el uso de espacios públicos y el enfoque de vivienda desde una perspectiva jurídica y social. 


\subsection{Impacto en el ordenamiento territorial}

En primer lugar, la aparición del COVID-19 en nuestra sociedad y los problemas que dicha enfermedad ha generado, conllevó a que diversos Estados revisen y ajusten de forma radical todos sus objetivos, políticas, principios e instrumentos técnicos y legales en materia de ordenamiento territorial, tales como los Planes de Ordenamiento Territorial —o su denominación equivalente en los diversos países-, lo cual indudablemente augura nuevos cambios en la forma de vivir de las personas (Ramírez 2020).

En cuanto al ordenamiento territorial, dicho concepto alude a aquel «proceso técnico, administrativo y político de toma de decisiones concertadas con los actores sociales, económicos, políticos y técnicos a fin de lograr una ocupación ordenada y un uso sostenible del territorio» (MINAM 2014). Esta definición considera las condiciones sociales, ambientales y económicas para la ocupación del territorio, así como el uso y aprovechamiento de los recursos naturales para garantizar un desarrollo equilibrado y en condiciones de sostenibilidad.

De este modo, respecto a los fenómenos en el territorio que configuran el concepto y marco de acción del ordenamiento territorial en el Perú, podemos mencionar los siguientes (Grupo Propuesta Ciudadana 2014):

- $\quad$ Alta concentración de la población, de las actividades productivas y del Estado en la capital y en otras ciudades: Como primer fenómeno, se describe al Perú como un territorio que progresivamente se ha vuelto sobrepoblado, destacando la ciudad de Lima como una megalópolis ${ }^{1}$ que contiene aproximadamente un tercio de la población nacional. Así, el país se ha ido caracterizando poco a poco como uno en el que la alta densidad demográfica se ha vuelto prácticamente inevitable.

Al mismo tiempo, las diversas ciudades al interior del país han ido adquiriendo un dinamismo importante, principalmente en materia económica y social (actividades productivas, concentración de grupos poblacionales), lo cual ha generado un sinnúmero de procesos migratorios desde las zonas rurales a fin de lograr una mayor búsqueda de oportunidades (a nivel laboral y educativo). Ello ha supuesto, entre otras cosas:

- La concentración de los servicios públicos, la presencia del Estado (en zonas urbanas principalmente), el desarrollo y concentración de infraestructura en determinados lugares.

- La concentración de altos niveles de pobreza en espacios urbanos y rurales, tales como ciudades, pueblos, centros poblados, entre otros; lo cual ha devenido en una amplia carencia de servicios básicos, escasa vitalidad y, en paralelo, una limitada presencia del Estado. 
- El casi total abandono de las zonas rurales, en particular de las zonas alto andinas y de la Amazonía.

- Desarrollo y crecimiento desordenado y sin planificación: Vinculado al primer fenómeno antes mencionado, este segundo fenómeno hace referencia a la ausencia de un sistema eficiente de planificación para el desarrollo nacional y articulado en los diferentes niveles de gobierno (nacional, regional y local), sumado a una constante y cada vez mayor desregulación de ciertas actividades económicas. Lo anterior ha generado, por tanto - y al contrario-, un desarrollo y crecimiento desordenado del territorio y de la población que la habita.

De modo particular, las situaciones generadas por esta ausencia de planificación como país son, entre otras:

- Una situación de informalidad y la ausencia de mecanismos eficientes de planificación demográfica, lo cual a su vez ocasiona el asentamiento de la población en zonas de riesgo, o donde se hace difícil o prácticamente imposible proveer servicios, principalmente servicios básicos (agua, desagüe, luz).

- Un escenario de creciente desigualdad de oportunidades o una presencia muy diferenciada del Estado entre unos lugares y otros en los cuales no existen los equipamientos necesarios y adecuados para solventar las necesidades de la población.

- Superposición de usos del territorio: Por último, y no menos importante, se ha presentado un fenómeno de superposición de usos del territorio, lo cual se expresa de la siguiente manera:

- $\quad$ La existencia de asentamiento de población en zonas arqueológicas o de riesgo (en este último caso, por ejemplo, en laderas o zonas de alta concentración de contaminación ambiental).

En segundo lugar, en cuanto a los principios que guían, orientan y delimitan el diseño, implementación y retroalimentación del ordenamiento territorial, podemos destacar los siguientes (MINAM 2013):

- La sostenibilidad del uso y la ocupación ordenada del territorio en armonía con las condiciones del ambiente y de seguridad física a través de un proceso gradual de corto, mediano y largo plazo, enmarcados en una visión de logro nacional.

- La integralidad, teniendo en cuenta todos sus componentes físicos, biológicos, económicos, sociales, culturales, ambientales, políticos y administrativos, con perspectiva de largo plazo. 
- La complementariedad en todos los niveles territoriales, propiciando la articulación de las políticas nacionales, sectoriales, regionales y locales.

- El respeto a la diversidad cultural, los conocimientos colectivos, y las formas de uso y manejo tradicionales del territorio y los recursos naturales, en concordancia con lo establecido en el artículo 89 de la Constitución Política del Perú.

Habiendo analizado los principales aspectos que configuran y delimitan el ordenamiento territorial, conviene explicar a continuación cuáles son los principales cambios que el contexto de pandemia por el COVID-19 supone para aquellos. De esta manera, podemos decir que las proyecciones de la estructura urbana que se han venido realizando de manera histórica y progresiva por las diversas autoridades, han sufrido un cambio drástico, y se pueden resumir en los siguientes términos:

\subsubsection{En relación a los fenómenos del territorio}

Alta concentración de la población, de las actividades productivas y del Estado en la capital y en otras ciudades

- Se ha producido una mayor y creciente concentración de personas en zonas o espacios por lo general pequeños, tales como viviendas, mercados, oficinas, entre otros, a raíz del aislamiento social obligatorio.

- Se ha presentado una reducción de actividades económicas en general, aunque con una paulatina recuperación en atención a las medidas dictadas por el Gobierno.

\section{Desarrollo y crecimiento desordenado y sin planificación}

- Las regiones que han presentado menor desarrollo y crecimiento se han visto más afectadas como consecuencia del COVID-19 y de las medidas de aislamiento social dictadas por el Gobierno.

- Las nuevas necesidades (vivienda, trabajo, salud) que se han presentado en las regiones con menor desarrollo y crecimiento, producto del aislamiento social, han generado como consecuencia más procesos de migración hacia las regiones más favorecidas por el Estado.

- Sumado a la informalidad en materia de ocupación de terrenos mediante las invasiones y la compra de «posesión» de estos últimos, se ha consolidado la precariedad en materia laboral debido a los despidos masivos de trabajadores, funcionarios y servidores públicos en general en el sector público y privado. 


\subsubsection{En relación a los principios}

A raíz de los efectos producidos por el COVID-19, los principios del ordenamiento territorial requieren ser reinterpretados y aplicados desde una perspectiva de seguridad y salud pública que permita un adecuado distanciamiento social y salubridad, lo cual deberá estar en equilibrio con el desarrollo y crecimiento económico que se genere producto de la reactivación de los sectores y actividades económicas.

Para lograr ello, resulta necesario pensar en nuevas alternativas sobre la gestión del territorio y que se relacionan directamente con los sectores económicos, sobre todo en aquellos más afectados (transporte, vivienda, turismo, minería, entre otros), a efectos de poder lograr una nueva y segura convivencia social.

Por lo tanto, en lo que se refiere al ordenamiento territorial, no cabe duda de que los retos trazados son diversos y complejos; razón por la cual se requiere no solo de un actuar coordinado de los diversos actores públicos y privados involucrados, sino también de una efectiva coordinación y entendimiento de intereses respecto de dichos actores.

En ese sentido, consideramos que sin una correcta y efectiva participación conjunta y cooperación entre estos protagonistas, el planteamiento y aplicación de un nuevo ordenamiento territorial que se adapte al contexto actual y a las nuevas necesidades de la población estará destinado al fracaso.

\subsection{Impacto en el servicio de transporte público}

Entre el conjunto de actividades económicas más afectadas a raíz de la llegada del COVID-19 a nuestro país, el servicio de transporte público ha sido, sin duda, uno de los protagonistas. De esta manera, consideramos que son dos las principales consecuencias que se han presentado.

\subsubsection{Cambios en las condiciones mínimas de funcionamiento del transporte público}

En primer término, las medidas de aislamiento y distanciamiento social que se han implementado para contener el contagio del COVID-19 han determinado, en efecto, no solo un gran impacto negativo para el servicio de transporte público en términos económicos, sino también la necesidad de adaptar dicho servicio a las nuevas necesidades y exigencias políticas y sociales.

Como es bien conocido, el transporte público ha sido históricamente en el Perú un servicio destinado a facilitar la vida de las personas en comunidad, así como la base fundamental para el desarrollo económico en relación con, por un lado, las personas y empresas que brindan dicho servicio y, por otro lado, la población que se desplaza mediante dicho servicio para llegar a sus centros de labores. De esta manera, puede considerarse al transporte público como una actividad económica rentable en sí misma, toda vez que no ha necesitado de 
otro servicio para poder desarrollarse y consolidarse (Huapaya y Soto 2012). Pero, sin perjuicio de lo anterior, el transporte público se ha caracterizado en los últimos años por presentar diversos problemas vinculados principalmente a la informalidad y al desarrollo desordenado de sus diversas modalidades, lo cual se originó por diversas causas, entre ellas, los caóticos cambios a nivel político, económico y normativo. Motivo por el cual el servicio de transporte público en las ciudades ha venido siendo muy deficiente e inseguro.

Aunado a lo anterior, este esquema de desarrollo del transporte público urbano se ha visto gravemente perjudicado con la aparición del COVID-19. En un primer momento, producto del aislamiento social obligatorio dispuesto por el Gobierno, se impidió que el servicio se preste prácticamente en su totalidad. En un segundo momento, la posibilidad de brindar dicho servicio se realizó de manera excepcional (para movilizar a cierto sector de la población que realiza labores permitidas durante el aislamiento social). Y, en un tercer y último momento, con la reactivación gradual del servicio en su conjunto, se realizó garantizando que el mismo cumpla con una serie de requisitos mínimos de seguridad y salubridad que permitan salvaguardar la vida y salud de las personas.

Lo anterior, en efecto, produjo una serie de creaciones y cambios a nivel normativo y técnico. Desde la reducción de la capacidad de pasajeros por vehículo y la implementación de mecanismos de seguridad y salubridad en los vehículos (señalética, limpieza constante de buses, elementos de separación entre conductores y pasajeros), hasta la provisión de equipamientos que permitan prevenir el contagio del COVID-19 (mascarillas, protectores faciales, gel antibacterial), podemos afirmar que el transporte público no es ni será lo mismo. Si se busca que este perdure en el tiempo, deberá satisfacer todas las condiciones mínimas que se le exigen, garantizando su idoneidad y fiabilidad.

Y ello es así toda vez que la obligatoriedad de prestar dichas condiciones no responde únicamente al deber de cumplimiento de un mandato establecido por las autoridades nacionales, regionales y locales a través de protocolos, lineamientos, directivas u otros instrumentos normativos, sino también -y principalmentea la alta demanda de seguridad que requiere la población, la cual optará por no utilizar - en la mayoría de casos- dicho servicio en caso considere que su vida y salud se encuentran en grave peligro por la ausencia o deficiencia de dichas condiciones.

Por ende, concluimos que, en lo referido a la actividad de transporte público, dicho servicio ha sido y seguirá siendo —al menos por unos cuantos años más - uno de los más impactados por el COVID-19, y deberá convivir y ajustar su funcionamiento a las nuevas exigencias de seguridad y salubridad antes mencionadas, con la finalidad de poder subsistir y no verse superado por el mayor protagonismo de los mecanismos alternativos de movilidad. 


\subsubsection{Utilización de mecanismos alternativos de movilidad}

En segundo término, y de forma paralela a la primera consecuencia, se ha visto necesario por parte de algunas autoridades (principalmente municipalidades) reforzar la planificación e implementación de mecanismos alternativos de movilidad que permitan evitar la posibilidad de contagio del COVID-19, lo cual podría darse en mayor medida si se empleara el servicio de transporte público.

Así las cosas, a modo de ejemplo podemos mencionar el uso de bicicletas y ciclovías, las cuales han tenido a lo largo del tiempo un poco pero eficiente desarrollo en el Perú, especialmente en algunas ciudades. A lo anterior se suma el problema de la poca o nula conectividad entre las ciclovías ya implementadas, lo cual obedece a una deficiente coordinación entre los gobiernos locales y a un escaso conocimiento en materia de «redes» que permitan entrelazar este sistema alternativo con otros sistemas de similar naturaleza (scooters, motocicletas, entre otros).

Consideramos, no obstante, que dicha situación podría cambiar y mejorar ampliamente, dada la actual y urgente necesidad de garantizar la seguridad y salud pública de la población; con lo cual los ciudadanos podrían considerar más llamativo, eficiente y seguro utilizar una bicicleta en lugar de un bus saturado de personas que suponga un riesgo de contagio (Ramírez 2020).

Lo explicado anteriormente requiere, entre otros aspectos, de la creación de un marco normativo común o, en todo caso, de una revisión y adaptación de la normativa vigente en materia de dichos mecanismos alternativos de movilidad que se ajusten a los principales cambios que ha generado este contexto de pandemia. En cuanto a este último caso, podemos mencionar la ley 30936, Ley que promueve y regula el uso de la bicicleta como medio de transporte sostenible, y su Reglamento aprobado mediante decreto supremo 012-2020-MTC² dispositivos normativos que, si bien han servido como una interesante iniciativa en materia de transporte, actualmente resultan insuficientes para prevenir y reducir el índice de contagios generados por el COVID-19.

\section{Retos planteados para el urbanismo: repensando los espacios públicos}

Hoy en día afrontamos un desafío sin precedentes. Desde el siglo pasado, con la aparición de la gripe española (1918-1920), el mundo no se ha visto seriamente afectado por una pandemia como hasta ahora. La aparición del COVID-19 generó un gran impacto en la vida de las personas, haciendo cambiar su manera de interactuar con sus pares y su entorno. Tanto es así que pasamos de realizar actividades fuera de casa y asistir a espacios aglomerados a una nueva forma de

\footnotetext{
2 Publicados en el Diario Oficial El Peruano con fechas 24 de abril de 2019 y 3 de junio de 2020, respectivamente.
} 
vivir que adopta el distanciamiento social, llegando a preferir en algunos casos el confinamiento.

Por otro lado, desde inicios de este año, varios grupos de personas a nivel mundial comenzaron a retirarse de la vida urbana y decidieron adoptar diversas y distintas medidas para salvaguardar su salud y la de sus seres queridos. En muchos países — como el caso de Perú - se tomaron medidas de confinamiento social obligatorio; mientras que en otros, las personas, de manera voluntaria, decidieron hacerlo. Ello llevó a que los espacios públicos quedaran paralizados e inutilizados, y la interacción de los ciudadanos con estos se torne limitada.

Sin embargo, por la misma necesidad de salir en busca del sustento diario y la progresiva reactivación de diversas actividades económicas, la calidad y seguridad que el espacio público puede prestar a la ciudadanía se vuelve fundamental. Como bien ha señalado la ONU-Habitat (2020): «Claramente, los espacios públicos deben ser parte de la respuesta al virus, ya sea para limitar la propagación del virus o para proporcionar formas para que las personas se relajen o lleven a cabo su sustento». No obstante ello, ¿cómo volvemos a adquirir confianza en los espacios públicos?

El distanciamiento social es la mejor arma que tenemos para evitar el contagio del COVID-19. Por ello, las principales autoridades y organismos a nivel internacional recomiendan que las personas guarden un espacio de separación mínima el uno del otro en los espacios públicos. Si bien expandiendo y reorganizando las calles es posible conseguirlo, debemos ser conscientes de que, en el caso del Perú, no todos pueden afirmar que cuentan con espacios públicos de calidad.

La pandemia, precisamente, evidenció los serios defectos de espacios públicos en nuestro país y, en algunos casos, su total ausencia. Entender ello resulta relevante a efectos de poder buscar formas de cambiar dicha situación, empezando por diseñar marcos normativos adecuados que - tomando como insumos las necesidades de la población y los diversos estudios técnicos sobre los espacios públicos-, permitan restablecer poco a poco esta relación personaentorno que se ha visto afectada por la pandemia.

En palabras del grupo Observatorio Lima Cómo Vamos:

Repensar de forma resiliente nuestros barrios y ciudades es parte importante de enfrentar los efectos de la pandemia en las actividades colectivas, el acceso al trabajo, la calidad de vida y el bienestar individual de las personas. Sin embargo, esta oportunidad de transformar nuestros espacios públicos no debe perder de vista los diversos contextos de desigualdad, violencia y vulnerabilidad de nuestras ciudades (Observatorio Lima Cómo Vamos 2020). 


\section{Retos planteados para la vivienda: construyendo un nuevo enfoque}

La expansión global del COVID-19 llevó a implementar distintas medidas rápidas y creativas para reducir la curva de contagio y mortalidad en diversos países del mundo. En esa línea, la vivienda se convirtió en el espacio físico más seguro ante la propagación del virus. No obstante, este no fue su único aporte. La vivienda pasó a tener un rol más notorio e importante en nuestras vidas, permitiendo la convivencia y la continuidad de nuestras actividades diarias.

Sin embargo, no todos cuentan con la suerte de tener una vivienda que cumpla con condiciones que permitan continuar el desarrollo personal, familiar, educativo, laboral y cultural del ser humano. La arquitectura de las viviendas no estaba destinada ni mucho menos preparada para responder a las necesidades y actividades múltiples de las personas. A nivel de arquitectura, las viviendas no fueron construidas como espacios propicios para actividades de ocio y encuentros sociales, ni para estudiar o trabajar. Tampoco fueron diseñadas desde un pensamiento urbano y la pandemia del COVID-19 ha ayudado a resaltar necesidades que muchas veces pasábamos por alto (Nikos 2020).

Según la Asociación de Empresas Inmobiliarias del Perú (ASEI), en los últimos años los peruanos han preferido departamentos cada vez más pequeños, entre $40 \mathrm{~m}^{2}$ y $80 \mathrm{~m}^{2}$ de área ocupada. Si bien la idea de adquirir departamentos con menos dimensiones puede responder a limitaciones económicas, a normas permisivas o a la oferta del mercado, no es menos cierto que el comprar unidades inmobiliarias con dimensiones pequeñas es sinónimo de ahorro a nivel económico (reducción en el pago de servicios de luz, mantenimiento, menor compra de objetos para el hogar, menos gasto en decoración, etcétera) y reducción de espacios sin uso, ya que se buscará aprovechar cada área al máximo. No obstante, la pandemia ha puesto en evidencia el gran valor del espacio doméstico y de las áreas comunes como elementos de carácter no solamente ornamental o paisajístico, sino también como piezas clave que complementan el desarrollo de las personas con fines educativos, laborales y/o recreativos.

En ese sentido, creemos que la actual crisis sanitaria nos deja un aspecto positivo en lo relativo a la necesidad de repensar el actual enfoque de vivienda y de su importancia fundamental como pieza en el desarrollo de diversos derechos fundamentales como son el derecho a la salud, educación, trabajo, libertad, entre otros.

En particular, consideramos urgente y necesario establecer una regulación normativa, así como redefinir mediante estudios, investigaciones, seminarios, conversatorios (entre otros), los siguientes aspectos:

\subsection{Diseño y construcción de edificaciones}

Sin duda, la vivienda es uno de los protagonistas principales en este periodo de emergencia sanitaria. Su importancia se ha incrementado significativamente por 
ser el lugar más seguro en el que podemos estar. Por ello, la idea de que cumplan con requisitos mínimos que permitan el desempeño de la vida diaria es esencial (Cuerdo 2020). Algunos de ellos son los siguientes:

- Aumentar áreas mínimas: La pandemia ha demostrado que las viviendas deben contar con ambientes tranquilos, cómodos y aislados de ruidos u otros elementos que impidan la realización de labores de oficina o académicas.

- Acceso a paisajes públicos: Es necesario que las viviendas cuenten con ventanas o balcones que permitan mantener conexión con la ciudad. Estos espacios sirven como espacios de recreación, deportivos o de encuentro con vecinos y demás personas.

- Zonas de estacionamiento para bicicletas: La actual situación y la necesidad de transportarnos ha llevado a revalorar el uso de bicicletas como medio alternativo y más seguro ante la propagación del COVID-19. En ese sentido, resulta relevante contar con áreas de estacionamiento para estos vehículos de uso personal.

- Zonas de recepción de productos: El e-commerce y los servicios de entrega a domicilio se volvieron las principales herramientas para evitar acudir a principales focos de contagio del COVID-19. Contar con áreas destinadas para la recepción, almacenamiento, desinfección y conservación constante de estos productos resulta importante.

- Conexión a internet: En la medida que la mayoría de actividades pasaron a realizarse dentro de la vivienda, la interconectividad a través de medios tecnológicos es esencial para la continuidad de nuestras labores y relaciones sociales. Por ello, contar con un servicio de internet y que este tenga las características adecuadas (buena velocidad, conexión, continuidad, entre otras) resulta esencial.

\subsection{Habilitaciones urbanas}

Según el Índice de Pobreza Multidimensional 2018, publicado por la ONU, en el Perú aproximadamente 4 millones de personas no cuentan con una vivienda ni acceso a servicios básicos (RPP 2018). Situación que significa un gran riesgo a su salud y de las demás personas, más aún en contextos como el que estamos viviendo. En estos casos, las habilitaciones urbanas resultan un procedimiento clave en la implementación de nuevos suelos urbanos con equipamientos e infraestructura necesaria y adecuada para el mejoramiento del país.

En pocas palabras, mediante la figura de la habilitación urbana se pueden implementar espacios que cumplan con requisitos mínimos de higiene, seguridad, salubridad, accesibilidad, suministros seguros y estables, y confort. Por lo tanto, este instrumento jurídico y técnico requiere ser más utilizado y mejorado. 


\subsection{Informalidad del suelo y las viviendas}

Otro punto relevante es la informalidad en el Perú. En nuestro país, según informó la Cámara Peruana de la Construcción (CAPECO), tenemos 70\% de viviendas que se ejecutan sin contar con licencia de edificación. Además, 30\% de las edificaciones no cuentan con habilitación urbana (RPP 2017).

Esta situación genera un problema adicional para su regulación y la obtención de sus títulos de propiedad. Debido a la informalidad, el acceso a servicios básicos queda limitado. La deficiencia de políticas públicas que se preocupen por esta población es un problema grave que ya estaba identificado desde mucho tiempo atrás y que la pandemia hizo más notoria.

De esta manera, en atención a los tres puntos antes señalados, podemos concluir que la importancia de la vivienda no solamente ha quedado demostrada y acentuada, sino que también resulta prioritario darle un nuevo enfoque jurídico y social que complemente y refuerce su rol como un espacio de desarrollo pleno de la persona, así como, en este contexto particular, de refugio y protección.

\section{Reflexiones Finales}

A modo de síntesis presentamos seis puntos a manera de reflexiones finales sobre los retos más importantes que ha trazado la pandemia del COVID-19 respecto al rol del derecho urbanístico y los ejes que lo conforman.

El primero de ellos forma parte del pronunciamiento «Hacia una nueva normalidad con menos desigualdad urbana» (2020), el cual suscribimos ${ }^{3}$.

1. La pandemia está evidenciando la enorme desigualdad en el Perú y las precarias condiciones en las que vive la mayor parte de peruanos: sin acceso de calidad al agua y desagüe; en viviendas hacinadas y precarias, carentes de espacios públicos adecuados y con áreas verdes insuficientes; sin seguridad laboral; con bajo nivel educativo; con un sistema de salud muy debilitado; y enormes limitaciones en transporte y accesibilidad. Por ello se propone:

- Aprobar una Ley de Desarrollo Urbano Sostenible y una Ley de Suelo, incorporando herramientas de gestión para reducir la desigualdad y afrontar el cambio climático en nuestras ciudades desde un enfoque intercultural.

\footnotetext{
3 Pronunciamiento ante la crisis sanitaria y social de las ciudades, y la necesidad de acciones prioritarias y estructurales por parte de los distintos niveles de gobierno para la construcción de un «sistema nacional de centros urbanos» efectivo, que sea motor de una economía diversificada y descentralizada, mejorando así las condiciones de vida de todos los ciudadanos y ciudadanas.
} 
- $\quad$ Asegurar que la sociedad civil tenga participación directa y activa en la elaboración y revisión de los planes urbanos del país.

- $\quad$ Proponer una política urbana que enmarque, a su vez, la política de vivienda y Reforzar la inversión en vivienda social más allá de los intereses privados.

- Reiniciar la ejecución de proyectos de agua y saneamiento asequibles en zonas urbanas con saneamiento legal, priorizando las obras de expansión de cobertura, rehabilitación y mejoramiento de redes de infraestructura en todo el Perú, atendiendo las áreas desabastecidas y habilitando zonas de expansión con vivienda social.

- Implementar un Sistema de Espacios Públicos que priorice a las poblaciones vulnerables en el marco del enfoque de género vinculando estrategias multisectoriales de gestión territorial.

- Impulsar una Reforma Integral de Transporte Urbano Nacional, con estrategias de movilidad, sostenible, multimodal e inclusiva (vías peatonales, aceras amplias, ciclovías y electro movilidad) priorizando el transporte público masivo con cobertura, frecuencia y accesibilidad (Hacia una nueva normalidad con menos desigualdad urbana 2020).

2. La pandemia generada con la aparición del COVID-19 ha supuesto un redimensionamiento de los más importantes cimientos o ejes que conforman la base del derecho urbanístico, lo cual ha conllevado al establecimiento de nuevos, diversos y distintos retos para esta importante rama del derecho administrativo.

3. En cuanto a los retos planteados al ordenamiento territorial, se destaca la necesidad de revisar, ajustar y reinterpretar los principales aspectos que definen, orientan y condicionan dicho concepto (fenómenos y principios). Actividades que, para lograr su adecuada adaptación al contexto actual del COVID-19, requieren de una participación conjunta, coordinada y común de los principales actores públicos y privados directamente involucrados en su implementación.

4. Sobre los retos impuestos a la visión de los espacios públicos, resaltamos la trascendencia de restablecer, mediante mecanismos adecuados y apropiados, el vínculo existente entre la sociedad y los espacios públicos que la rodean, a fin de mejorar la calidad de vida y aprovechamiento de ambas partes, respectivamente.

5. Respecto a los retos trazados sobre el enfoque de la vivienda, consideramos urgente y prioritario redefinir — tanto a nivel teórico como práctico, y desde una perspectiva jurídica y social - el rol que juega la vivienda, y que sea susceptible de adaptarse a las nuevas exigencias planteadas por el COVID-19. En concreto, recomendamos hacer énfasis en aspectos como el mejoramiento del diseño y construcción de edificaciones, la mejora y mayor aplicación de las habilitaciones urbanas, y la preocupante situación generada por el fenómeno de la informalidad del suelo. 
6. Consideramos, finalmente, que esta pandemia nos obliga a un replanteamiento estructural e integral del Estado, la gobernanza y el derecho hacia nueva normalidad, con ciudades más seguras, justas y solidarias para lograr un desarrollo urbano sostenible.

\section{Referencias}

Cuerdo, M. T. (2020, 12 de mayo). Repensar la vivienda tras la pandemia. The Conversation. Recuperado de https://theconversation.com/repensar-lavivienda-tras-la-pandemia-137276

Grupo Propuesta Ciudadana (2014). El Ordenamiento Territorial en el Perú. Avances y retos para las regiones y el país. Primera edición. http:// propuestaciudadana.org.pe/sites/default/files/publicaciones/archivos/ Cartilla\%20El\%200rdenamiento\%20Territorial\%20en\%20el\%20 Per\%C3\%BA.pdf

Hacia Una Nueva Normalidad Con Menos Desigualdad Urbana (2020). [Petición Online]. Change.org. Recuperado de https://www.change.org/p/estadoperuano-hacia-una-nueva-normalidad-con-menos-desigualdad-urbana.

Huapaya, M., y Soto, E. (2012). De todos y de nadie: el caso del Transporte Público en Lima y Callao y la necesidad de un planeamiento común. Círculo de Derecho Administrativo, 12: 331-336.

García Novo, A. (9 de junio de 2020). Cómo cambiarán las ciudades y el urbanismo tras COVID-19. Huellas by Sareb. //www.huellasbysareb.es/en-primerapersona/ciudades-despues-covid/

Ministerio del Ambiente (2013). Lineamientos de Política para el Ordenamiento Territorial. Segunda edición. http://www.minam.gob.pe/ ordenamientoterritorial/wp-content/uploads/sites/129/2017/02/09.Lineamientos-de-Politicas-2da-Edicion-2013.pdf

Ministerio del Ambiente (2014). Orientaciones básicas sobre el Ordenamiento Territorial en el Perú. Primera edición. https://centroderecursos. cultura.pe/sites/default/files/rb/pdf/OrientacionesbAsicassobre-elOrdenamiento-Territorial\%20en\%20el\%20Peru.pdf

Nikos, M. (2020, 10 de mayo). La importancia del espacio doméstico en tiempos de COVID-19. En Arch Daily, el sitio web de arquitectura más leído en el mundo. Última consulta el 5 de noviembre de 2020. https://www.archdaily. pe/pe/938788/la-importancia-de-la-forma-del-espacio-domestico-entiempos-de-covid-19

Observatorio Lima Cómo Vamos (26 de junio de 2020). Repensar, rediseñar, reiniciar el espacio público para resistir a la pandemia. Lima Cómo Vamos. https://www.limacomovamos.org/noticias/repensar-redisenar-reiniciarel-espacio-publico-para-resistir-a-la-pandemia/

Organización de las Naciones Unidas - Habitat (ONU). (2020). Espacio Público y COVID-19.https://unhabitat.org/sites/default/files/2020/06/spanishfinal_ public_space_key_messages_covid19.pdf 
Organización Mundial de la Salud (OMS). (s.f.). Preguntas y respuestas sobre la enfermedad por coronavirus (COVID-19). https://www.who.int/es/ emergencies/diseases/novel-coronavirus-2019/advice-for-public/q-acoronaviruses

Ortiz Sanchez, J. (2017). Introducción al Derecho Urbanístico. Colección Lo esencial del Derecho, (23). Lima: Fondo Editorial PUCP.

Ramírez, M. (2020, 4 de junio). Covid-19, Ordenamiento Territorial y Planificación Urbana en Latinoamérica. En Arch Daily, el sitio web de arquitectura más leído en el mundo. Última consulta el 5 de noviembre de 2020. https:// www.archdaily.pe/pe/940794/covid-19-ordenamiento-territorial-yplanificacion-urbana-en-latinoamerica

RPP (26 de septiembre 2017). Capeco: El 70\% de viviendas en Lima son informales y vulnerables a un terremoto. Última consulta el 5 de noviembre de 2020. https://rpp.pe/economia/economia/capeco-el-70-de-viviendas-en-limason-construidas-sin-normas-tecnicas-noticia-1078934

RPP (12 de octubre 2018). Hay 4 millones de peruanos pobres por sus condiciones de vida. Última consulta el 5 de noviembre de 2020. https://rpp.pe/ economia/economia/hay-4-millones-de-peruanos-pobres-por-suscondiciones-de-vida-noticia-1156158 